\title{
A telecolaboração como contexto para a formação de professores
}

DOI: http://dx.doi.org/10.21165/el.v50i3.2970

\author{
Daniela Nogueira de Moraes Garcia'
}

\section{Resumo}

Tecnologias, globalização e internacionalização revelam perspectivas promissoras no cenário das línguas estrangeiras. O presente trabalho aborda a telecolaboração no ensino superior no contexto das línguas e formação de professores. O teletandem viabiliza parcerias para a realização de sessões bilíngues de conversação. Considerando que, também, oportuniza um espaço profícuo para a expansão dos conteúdos, a autonomia e postura crítico-reflexiva, reconhecemos a relevância de professores pré-serviço integrarem as sessões de teletandem. Sob um olhar qualitativo de cunho interpretativista, apresentamos um recorte de dados de estudantes de Letras para observar o uso e impacto das tecnologias em sua formação e a participação na telecolaboração. Os resultados apontam para o potencial das tecnologias e ações de intercâmbio virtual para incrementar a atuação futura dos professores pré-serviço.

Palavras-chave: telecolaboração; formação de professores; tecnologias.

1 Universidade Estadual Paulista "Júlio de Mesquita Filho" (UNESP), Assis, São Paulo, Brasil; dany7garcia@gmail.com; https://orcid.org/0000-0003-2813-7538 


\title{
Telecollaboration as a context for teacher education
}

\begin{abstract}
Technologies, globalization, and internationalization reveal promising perspectives in the foreign language scenario. This paper focuses on telecollaboration in higher education considering languages and teacher education. Teletandem provides partnerships for bilingual conversation sessions. Considering that it also provides a productive context for expanding the syllabus, autonomy, and critical reflective thinking, we realize the relevance of pre-service teachers to take part in teletandem sessions. Under a qualitative interpretativist basis, we present some data from the Languages and Literature students to observe the use and the impact of technologies in teacher education and telecollaboration. The results point to the potential of technologies and virtual exchange activities to maximize the future educational practice of pre-service teachers.
\end{abstract}

Keywords: telecollaboration; teacher education; technologies.

\section{Introdução}

As tecnologias digitais de informação e comunicação, doravante TDICs, têm perpassado todos os setores de nossa sociedade, influenciando, de forma robusta, a realização de tarefas cotidianas. Sendo assim, devemos nos debruçar sobre o cenário educacional de forma que se promova um diálogo entre conteúdos, práticas pedagógicas e as inovações tecnológicas do presente século.

Como sugerem Moran, Masetto e Behrens (2013), reconhecemos, com as tecnologias atuais, a importância de um realinhamento de práticas para criar possibilidades, desenvolver competências, promover aprendizagens significativas para motivar os alunos e potencializar os espaços de formação.

Aragão e Cajazeira (2015) apresentam uma compreensão apropriada acerca da necessidade de novas práticas. Para os autores:

As atuais tecnologias da informação e comunicação demandam da formação de professores novas práticas e a lide com diversas linguagens. Neste cenário e movido pela força motriz da globalização e da complexificação tecnológica acelerada, um perfil profissional no ensino/aprendizagem de línguas tem sido desenhado. Por outro lado, encontramos na história do pensamento ocidental sobre linguagem, cultura e conhecimento, conceitos e práticas que desafiam a inserção destas práticas sociais com novas linguagens e tecnologias na academia e na formação de professores. (ARAGÃO; CAJAZEIRA, 2015, p. 302). 
Alinhamos o pensamento com Almeida (2018, p. x), quando afirma que:

Assim, é essencial uma educação que ofereça condições de aprendizagem em contextos de incertezas, desenvolvimento de múltiplos letramentos, questionamento da informação, autonomia para resolução de problemas complexos, convivência com a diversidade, trabalho em grupo, participação ativa nas redes e compartilhamento de tarefas. Por isomorfismo, a formação do professor também deve se pautar pela atividade criadora, reflexiva, crítica, compartilhada e de convivência com as diferenças, usando as mídias e as tecnologias como linguagem e instrumento da cultura, estruturantes do pensamento, do currículo, das metodologias e das relações pedagógicas.

Nesse sentido, concebemos que o panorama da formação de professores deva fomentar uma multiplicidade de ações e perspectivas, com o suporte das TDICs. Dessa forma, os professores pré-serviço ${ }^{2}$ poderiam ter experiências significativas e transformadoras e priorizar práticas que valorizem os alunos e as demandas atualizadas para, em sua atuação futura, desvencilhar-se de modelos cristalizados que ignoram a construção do conhecimento.

Considerando os conceitos de nativos e imigrantes digitais (PRENSKY, 2001), VetromilleCastro e Ferreira (2016, p. 156) questionam "o quanto os professores em formação têm discutido formalmente o uso de TICs na aprendizagem de línguas e na educação (inicial ou continuada) de professores". Segundo os autores:

O ponto nevrálgico a debater é, frisamos, o quanto os cursos de formação docente estão preparando os professores de línguas para atuarem nas redes (neuros) sociais e, como consequência, construírem conhecimento e proporcionarem - em suas práticas profissionais - espaço para a produção de saberes. (VETROMILLECASTRO; FERREIRA, 2016, p. 160).

Entendemos, assim, que o engajamento de professores pré-serviço em ações pautadas nas tecnologias pode possibilitar o ensino/aprendizagem de línguas e o exercício da autonomia e da reflexão e, dessa forma, oportunizar um embasamento significativo que será refletido na futura docência.

Identificada a relevância de olhar para os contextos de formação e o uso das tecnologias na universidade, o presente trabalho enfoca a formação de professores e a telecolaboração como forma de contemplar, também, as demandas de acesso às línguas e culturas. Para

20 presente trabalho compreende professores pré-serviço como professores em formação docente, cursando a licenciatura em Letras. 
tal, abordamos o referencial teórico de formação de professores, da colaboração on-line e do teletandem. Em seguida, exploramos, sob uma ótica qualitativa e interpretativista, um recorte de dados de estudantes do curso de Letras, professores pré-serviço. Concluímos o trabalho com algumas considerações acerca da análise conduzida e de perspectivas do impacto das tecnologias no cenário educacional de línguas e formação docente.

\section{Referencial teórico}

Contextos de formação e prática docente ganham atenção dada sua importância nas esferas educacionais e, aliados às tecnologias, apontam para avanços e perspectivas emergentes de crescimento.

Compreendendo que o panorama de formação de professores deva propiciar uma articulação entre teoria e prática de modo que os envolvidos vivenciem o conhecimento de forma diferenciada e expressiva, Garcia, Fioruci e Freitas (2020, p. 125) esclarecem que "[a] experiência com o ensino e aprendizagem por intermédio das novas tecnologias é bastante significativa para futuros professores, tratando-se de ações pedagógicas e em línguas estrangeiras".

Alarcão (2011, p. 63) esclarece que o "conhecimento que resulta da sua compreensão e interpretação permitirá a visão e a sabedoria necessária para mudar a qualidade do ensino e da educação". Dessa forma, os estudantes em processo de formação, compreendendo e interpretando, podem presenciar e, até mesmo, protagonizar aprendizados que, certamente, ecoarão em práticas docentes futuras.

Para Rezende Jr. e Messias (2020, p. 43), "[a] utilização de recursos tecnológicos no ensino e na formação de professores de línguas tem demonstrado ser uma ferramenta eficaz quando prioriza a interação e o uso real da língua". Vislumbramos a pertinência da utilização dos referidos recursos e, também, do engajamento do aluno, em consonância com os autores.

Por todo o mundo, as ações colaborativas com o suporte do computador têm, há algumas décadas, despertado interesse de estudiosos e se constituído cerne de pesquisas. Assim, podemos conjecturar tais ações como possibilidade para opulentar a formação de professores.

De acordo com O’Dowd (2018, p. 1, tradução nossa $\left.{ }^{3}\right)$,

3 No original: "Telecollaboration, or 'virtual exchange', are terms used to refer to the engagement of groups of learners in online intercultural interactions and collaboration projects with partners from other cultural contexts or geographical locations as an integrated part of their educational programmes". 
A telecolaboração ou 'intercâmbio virtual' são termos utilizados para se referir ao engajamento de grupos de aprendizes em interações interculturais on-line e projetos colaborativos com parceiros de diferentes contextos culturais ou localidades como parte integrante de seus programas educacionais.

É importante salientar que não basta simplesmente unir aprendizes de diferentes países para alcançar benefícios de aprendizagem (RYDER; LYNCH, 2014). A telecolaboração, colaboração on-line ou intercâmbio virtual são termos intercambiáveis e suas ações devem trazer seus propósitos bem delineados, junto a instrutores e aprendizes, de modo que não se traduzam, apenas, em encontros virtuais entre pessoas de diferentes países ou instituições.

O teletandem constitui-se em uma prática telecolaborativa que se originou da aprendizagem em tandem (BRAMMERTS, 2003; DELLILE; CHICHORRO FERREIRA, 2002), comum na Europa desde os anos 60. De acordo com Little et al. (1999, p. 1), tandem é "uma forma aberta de aprendizagem que envolve dois aprendizes de línguas nativas diferentes que trabalham juntos no intuito de aprender a língua do outro".

Três princípios envolvem a prática com vistas ao sucesso (ou não) das parcerias: a reciprocidade (benefícios mútuos), o uso separado de línguas (equidade linguística) e a autonomia (responsabilidade pela própria aprendizagem), segundo Schwienhorst (1998).

As sessões de tandem são compostas de duas partes, uma para cada língua, pois assim os parceiros são encorajados a falar a língua-alvo e garante-se que ambos tenham a oportunidade de praticar, desafiando-os a falarem na língua estrangeira, mesmo que falar em sua língua de proficiência seja mais eficaz para atingir seus objetivos de comunicação (BRAMMERTS, 2003).

Inspirado na aprendizagem em tandem, o teletandem constitui-se cenário promissor para acesso aos falantes estrangeiros, suas línguas e culturas e, também, para a formação de professores. Telles (2015, p. 604) define que "[...] teletandem é um contexto virtual, autônomo e colaborativo no qual dois falantes de línguas diferentes utilizam recursos de tecnologia VOIP (texto, voz e imagem de webcam) para ajudar o parceiro a aprender a sua língua materna (ou linguagem de proficiência)".

Dessa maneira, ao interagir com um parceiro estrangeiro, os próprios parceiros exercem a responsabilidade por sua experiência, gerenciam e vivenciam a construção do conhecimento.

No Brasil, as sessões de mediação (SALOMÃO, 2012) ocorrem, geralmente, logo após as interações e constituem-se momento para compartilhamento da aprendizagem, 
exposição de dúvidas ou dificuldades e discussões coletivas entre os participantes e os professores/pesquisadores/mediadores ${ }^{4}$. Dessa maneira, observa-se espaço para fomentar a avaliação, feedback, exercício de reflexão para que a experiência seja maximizada.

Compreendemos, a partir das ideias de Aragão e Cajazeira (2015), que o teletandem e as sessões de mediação propiciam que o professor pré-serviço integre esferas diferenciadas do ensino/aprendizagem que Ihe permitem refletir sobre sua prática, além de buscar alternativas transformadoras para a construção do conhecimento.

Garcia, Fioruci e Freitas (2020) reconhecem a necessidade de os alunos do curso de Letras, futuros professores, acompanharem as mudanças da sociedade tecnologizada e consideram o teletandem como espaço propício e pedagógico para tal vivência. Em consonância com as autoras, concluímos que, em relação às perspectivas aqui elencadas, o teletandem, enquanto prática de intercâmbio virtual, apresenta potencial para atender demandas linguísticas, culturais e de formação docente. Ressalta-se que construiu uma importante trajetória em cenário brasileiro e mundial, comprovada pelas pesquisas e estudos desenvolvidos ${ }^{5}$ e, dessa maneira, constitui-se base para outras ações telecolaborativas.

Dessa forma, considerando a necessidade de articulação de experiências e cenários profícuos para a formação docente, compartilhamos um breve recorte de dados para observar o uso e impacto das tecnologias junto a estudantes do curso de Letras.

\section{Procedimentos metodológicos}

A perspectiva qualitativa (LÜDKE; ANDRÉ, 1986, DENZIN; LINCOLN, 1998; BURNS, 1999) sob a perspectiva interpretativista da hermenêutica (VAN MANEN, 1990; RICOEUR, 1981) permeou a coleta e análise dos dados.

O contexto do presente estudo é o curso de Letras de uma universidade pública do interior do estado de São Paulo. Os participantes são 16 professores pré-serviço, cursando do primeiro ao quarto ano, períodos diurno ou noturno e que, em geral, são envolvidos em várias outras ações do câmpus, como projetos de ensino, de pesquisa ou extensão, monitorias no Centro de Línguas, dentre outras. O quadro 1 demonstra, sob nomes fictícios, o panorama explicitado.

4 Retratamos, aqui, nosso contexto de atuação no Brasil. Em outras instituições e, até mesmo, no exterior, a condução e formato das sessões de mediação podem apresentar suas especificidades, por questões de logística.

5 Maiores informações em: www.teletandembrasil.org 
Quadro 1. Participantes da pesquisa

\begin{tabular}{|c|c|c|c|c|}
\hline & Diurno & Diurno & Noturno & Noturno \\
\hline $\mathbf{1}^{\mathbf{0}}$ ano & Natália & Beatriz & Bruno & Aline \\
\hline $\mathbf{2}^{\mathbf{0}}$ ano & Priscila & Márcio & João & Lívia \\
\hline $\mathbf{3}^{\mathbf{0}}$ ano & Fábio & Patrícia & Gisele & Vivian \\
\hline $\mathbf{4}^{\mathbf{0}}$ ano & Samanta & Jaqueline & Amanda & Luciano \\
\hline
\end{tabular}

Fonte: Elaboração própria

Os participantes são estudantes matriculados em disciplinas do curso de Letras, em sua maioria, cursistas de Língua Inglesa e, com os quais, a pesquisadora já estabeleceu algum tipo de contato, quer em projetos de ensino ou extensão, aulas da Graduação ou ações de telecolaboração. Assim, a partir de contato via e-mail ou redes sociais, foram, aleatoriamente, selecionados dois professores pré-serviço de cada ano e período e criados formulários on-line para buscar um mapeamento referente ao uso e impacto das tecnologias no processo de formação.

Os dados aqui compartilhados são referentes a dois questionários, um fechado (Q1) e um semiaberto (Q2) enviados por meio de formulário on-line, como mencionado, que abordaram questões de acesso e aplicação das tecnologias na formação. 0 quadro 2 detalha o conteúdo das perguntas propostas sob três eixos: processo de formação no curso de Letras, uso de tecnologias e papel do professor.

Quadro 2. Eixos e conteúdos das perguntas dos questionários Q1 e Q2

\begin{tabular}{|l|l|l|}
\hline \multicolumn{1}{|c|}{$\begin{array}{c}\text { Processo de formação no } \\
\text { curso de Letras }\end{array}$} & \multicolumn{1}{|c|}{ Uso de tecnologias } & \multicolumn{1}{c|}{ Papel do professor } \\
\hline $\begin{array}{l}\text { descrição de experiências, } \\
\text { durante a Graduação, } \\
\text { mediadas pelas tecnologias }\end{array}$ & $\begin{array}{l}\text { concepção sobre o uso e } \\
\text { suporte de tecnologias e } \\
\text { mídias digitais no ensino }\end{array}$ & $\begin{array}{l}\text { breve reflexão acerca do papel } \\
\text { do professor }\end{array}$ \\
\hline $\begin{array}{l}\text { realização ou não de ações } \\
\text { de intercâmbio virtual }\end{array}$ & $\begin{array}{l}\text { breve reflexão acerca da } \\
\text { função ou influências das } \\
\text { tecnologias na atuação } \\
\text { docente }\end{array}$ & $\begin{array}{l}\text { breve reflexão sobre a futura } \\
\text { atuação docente a partir da } \\
\text { formação recebida no curso } \\
\text { de Letras }\end{array}$ \\
\hline $\begin{array}{l}\text { percepção da utilização de } \\
\text { tecnologias nas aulas de } \\
\text { Graduação }\end{array}$ & $\begin{array}{l}\text { conhecimentos tecnológicos } \\
\text { anteriormente adquiridos } \\
\text { e em momento pandêmico } \\
\text { (explicitação de aplicativos, } \\
\text { mídias, plataformas, } \\
\text { programas) }\end{array}$ & \\
\hline
\end{tabular}




\begin{tabular}{|l|l|l|}
\hline $\begin{array}{l}\text { oferta de disciplinas, no } \\
\text { curso de Letras, com foco no } \\
\text { uso das tecnologias }\end{array}$ & $\begin{array}{l}\text { reflexão acerca das } \\
\text { tecnologias no ensino, } \\
\text { considerando momento de } \\
\text { pandemia e enfocando o aluno } \\
\text { e o professor }\end{array}$ & \\
\hline $\begin{array}{l}\text { relato do processo de } \\
\text { formação no curso de Letras } \\
\text { e uso de tecnologias a partir } \\
\text { da condição de professor } \\
\text { pré-serviço }\end{array}$ & & \\
\hline
\end{tabular}

Fonte: Elaboração própria

Diante do cenário exposto, observa-se que a sondagem, pelos três eixos, visou buscar informações para subsidiar o presente estudo que se debruça sobre o uso e impacto das tecnologias na formação docente e a participação e possíveis contribuições da colaboração on-line. Abordamos, a seguir, os dados compilados.

\section{Observando os dados}

Nesta seção, compartilharemos os dados coletados por meio dos questionários online (Q1 e Q2) de modo a mapear e melhor compreender o panorama da formação, tecnologias e telecolaboração no curso de Letras, ressaltando que não houve intervenção nas respostas recebidas e que as mesmas foram aleatoriamente selecionadas.

A pergunta 4 do questionário semiaberto solicitou, aos participantes, a descrição de experiências, na universidade, mediadas pelas tecnologias. Os respondentes apresentaram a participação em (a) sessões de intercâmbio virtual (teletandem ou telecolaboração), (b) eventos que recorreram ao suporte virtual, (c) oficinas, (d) uma disciplina específica ou aulas regulares presenciais na Graduação e (e) projeto extensionista. Considerando o momento atual, foram mencionadas a participação em (f) aulas ministradas de forma remota durante a pandemia do COVID-19, (g) palestras on-line síncronas (lives) ministradas por associações especializadas e a (h) utilização de aplicativos e plataformas. 
Gráfico 1. Experiências mediadas pelas tecnologias na graduação em Letras (Q2)

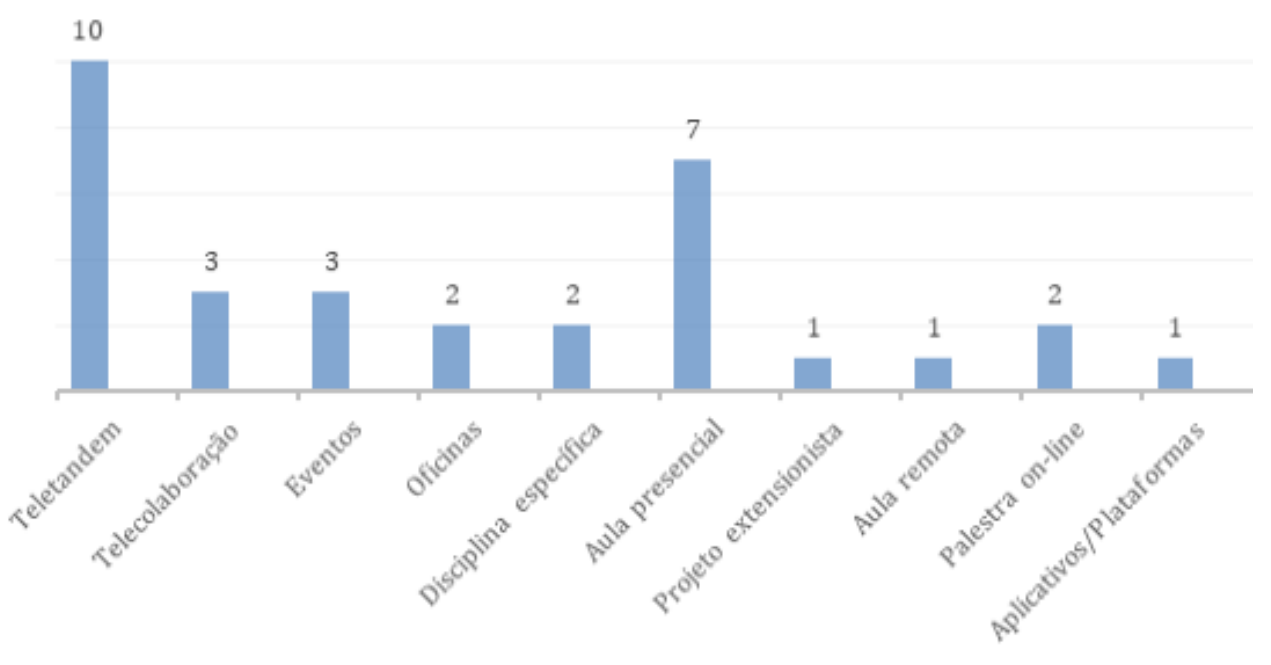

Fonte: Elaboração própria

Esclarecendo que alguns participantes indicaram mais de uma experiência tecnológica, deparamo-nos com duas respostas sobressalentes que são o teletandem e aula presencial e as abordaremos, segundo as respostas obtidas. Começamos pela última, as aulas ministradas no âmbito do curso de Letras de forma presencial.

Acerca da solicitação: "Detalhe ações de seus professores, nas aulas do curso de Letras, que abordam, usam, mencionam o uso das tecnologias", Patrícia e Samanta afirmam que:

Excerto 1. Q2 de Patrícia e Samanta (Professoras pré-serviço do $3^{\circ}$ e $4^{\circ}$ anos de Letras)

\begin{tabular}{|l|l|}
\hline Patrícia & $\begin{array}{l}\text { Num geral, todos os professores, em algum momento da disciplina que lecionam, } \\
\text { utilizam as tecnologias, por meio de slides em aula. Nas aulas de Língua Estrangeira, } \\
\text { sempre utilizamos o datashow para ouvir os listenings do livro ou para realizar } \\
\text { atividades da disciplina. Em aulas de Linguística, já utilizamos como meio de } \\
\text { realizarmos avaliações e enviar via e-mail }\end{array}$ \\
\hline Samanta & $\begin{array}{l}\text { Poucos são os professores que abordam o uso das tecnologias. Sendo sincera, o } \\
\text { máximo de contato que os professores têm com as TIC's é o PowerPoint e mesmo } \\
\text { assim, alguns nem disso utilizam. As aulas em que mais utilizamos tecnologias } \\
\text { são as de línguas, onde temos acesso a vídeos, jogos e músicas dentro da sala de } \\
\text { aula, fora isso, não consigo pensar em nenhuma outra disciplina que as utilize. [...] }\end{array}$ \\
\hline
\end{tabular}

Fonte: Elaboração própria

Apesar da recorrência da menção de uso de tecnologias em aulas presenciais, nota-se que tal não é considerado como grande inovação pelas professoras pré-serviço e nativas digitais. Patrícia aponta a utilização de slides, datashow e e-mail e Samanta menciona o PowerPoint e acesso a vídeos, jogos e músicas nas aulas de Língua Estrangeira. 
É possível notar a insatisfação de Samanta quando afırma que "Sendo sincera, o máximo de contato que os professores têm com as TIC's é o PowerPoint e mesmo assim, alguns nem disso utilizam". Ela parece demonstrar expectativas maiores em relação ao suporte de tecnologias em suas aulas da graduação.

As respostas do excerto 1 não demonstram perspectivas de interação, construção conjunta de conhecimento e protagonismo dos estudantes. O auxílio das tecnologias aqui mencionado é válido, mas pode ser maximizado se "propiciar maior interatividade e produção" (ARAGÃO; CAJAZEIRA, 2015, p. 303) e permitir um co-construir de conhecimento e um processo de ensino/aprendizagem de forma que não se perpetuem velhas práticas em novos suportes ou, como alerta Moran (2013), não se busque uma mesmice sob um verniz de modernidade.

Um olhar para as crenças dos professores poderia elucidar o cenário que aqui brevemente analisamos, por exemplo. Por outro lado, algumas questões, também, podem ser aqui elencadas para melhor compreender a situação exposta pelos professores pré-serviço, por exemplo, a sobrecarga de trabalho, a falta de intimidade e habilidade tecnológica do professor universitário, os currículos não muito flexíveis, etc.

Voltamo-nos, agora, para abordar o teletandem como prática de ambiência tecnológica mencionada pelos professores em formação. A partir das duas questões: "Descreva suas experiências, na universidade, que foram mediadas pelas tecnologias, por exemplo, teletandem, telecolaboração, elaboração de material didático com suporte das tecnologias, oficinas que frequentou, cursos com enfoque tecnológico dos quais participou, etc." e "Se fez teletandem ou telecolaboração, detalhe. Se não fez, responda 'nada consta'", foi possível mapear que, dos 16 respondentes, 10 afirmaram já terem praticado esta modalidade de intercâmbio virtual. Nos excertos de 2 a 4, os participantes discorrem acerca de suas experiências.

Excerto 2. Q2 de Lívia, Priscila e Beatriz (Professoras pré-serviço do $1^{\circ}$ e $2^{\circ}$ anos de Letras)

\begin{tabular}{|l|l|}
\hline Lívia & Fiz duas vezes: com a Universidade XX e a outra eu não me recordo o nome. A primeira \\
& vez que fiz foi com uma falante não nativa de língua inglesa e foi muito bacana. O \\
& nome dela era XX e ela me mostrou muito do seu local de origem como comida, \\
festas e até mesmo livros. A troca cultural foi muito grande. Quando eu fiz com a \\
Universidade XX eu conversei com XX, neste caso não foi igual o outro que era apenas \\
em inglês, fazíamos metade inglês e a outra metade do tempo foi em português. Foi \\
diferente. Com a XX nos brincávamos mais do que conversamos diretamente sobre \\
nossas vidas, o jogo que mais me recordo foi "duas verdades e uma mentira".
\end{tabular}




\begin{tabular}{|l|l|}
\hline Priscila & $\begin{array}{l}\text { Já fiz teletandem. Nesta experiência eu pude interagir e aprender outras culturas, } \\
\text { por meio do desenvolvimento da língua inglesa, prioritariamente. A comunicação me } \\
\text { fez perceber diferentes realidades, saindo de uma bolha social, descobrindo novos } \\
\text { meios, culturas e realidades, saindo de um espaço de conforto, diante de recursos } \\
\text { tecnológicos, que por vezes, facilitavam ou dificultavam a comunicação, porém } \\
\text { oportunizavam a interação [...]. }\end{array}$ \\
\hline Beatriz & $\begin{array}{l}\text { Fiz o teletandem XX no início do ano, era em março, eu me inscrevi na modalidade on- } \\
\text { line justamente pela comodidade de poder estar em casa e treinando meu inglês. Foi } \\
\text { uma experiência muito única, aprendi várias palavras novas e trocamos experiências } \\
\text { acerca da realidade do nosso país em variados aspectos, incluindo o ensino a } \\
\text { distância e a Covid-19. Meu parceiro morava em XX então nosso choque de realidade } \\
\text { era muito grande, e isso foi positivo para as nossas interações, pois tinha muita coisa } \\
\text { pra gente falar. }\end{array}$ \\
\hline
\end{tabular}

Fonte: Elaboração própria

No caso de Lívia, são retratadas duas experiências, uma de telecolaboração envolvendo inglês como língua franca, quando os dois participantes são aprendizes da língua inglesa, não sendo, nenhum dos dois, nativos e, também, uma de teletandem, com a prática de português e inglês na sessão. Lívia retrata a troca cultural advinda da interação. É possível observar, em sua resposta, o engajamento e motivação nas interações de forma a abordarem jogos como forma de aprendizagem.

Priscila menciona a interação, aprendizagem de outras culturas e o desenvolvimento da língua inglesa ao realizar sessões de teletandem. A percepção e descoberta de diferentes realidades são abordadas pela professora pré-serviço, assim como o fato de a experiência propiciar a saída de uma "bolha social" e de um "espaço de conforto".

Segundo Beatriz, sua participação no teletandem se deu em momento de pandemia e, de sua casa, realizando interações para a prática do inglês. Sua avaliação é bastante positiva, incluindo a aprendizagem de "palavras novas" e troca de experiências sobre sua realidade e a de seu par. Beatriz destaca um "choque de realidade" sob a compreensão de que tal fato enriqueceu as interações de modo a proporcionar muitos assuntos a serem abordados nas trocas linguísticas.

A questão cultural é recorrente para as três professoras pré-serviço, como se pode observar e, de fato, faz-se bem marcada no intercâmbio virtual entre línguas e instituições estrangeiras.

O excerto 3 retrata a experiência de Jaqueline, estudante do quarto ano do curso de graduação em Letras. 
Excerto 3. Q2 de Jaqueline (Professora pré-serviço do $4^{\circ}$ ano de Letras)

\begin{tabular}{|l|l|}
\hline Jaqueline & $\begin{array}{l}\text { Fiz teletandem e telecolaboração durante os quatros anos da faculdade. Foram } \\
\text { experiências incríveis, talveza melhor experiência direta com umalíngua estrangeira. } \\
\text { O teletandem foi essencial para que eu adquirisse maior desenvoltura e me sentisse } \\
\text { confortável, de fato, falando uma LE. O auxílio dos mediadores foi fundamental, } \\
\text { porque, assim, pude refletir sobre minhas telecolaborações e trazer assuntos cada } \\
\text { vez mais interessantes à minha/meu parceiro/parceira de teletandem. Além disso, } \\
\text { eles auxiliaram no uso das ferramentas para realizar as colaborações. }\end{array}$ \\
\hline
\end{tabular}

Fonte: Elaboração própria

A avaliação de Jaqueline é muito positiva e engloba sua trajetória na graduação já que afirma ter participado de ações de intercâmbio virtual ao longo de quatro anos. Para ela, o teletandem proporcionou desenvoltura para a comunicação intercultural e, também, com suporte dos professores/pesquisadores/mediadores, fomento à reflexão e auxílio com temáticas e uso de ferramentas. Podemos pensar que, ao vivenciar tais situações, a professora pré-serviço Jaqueline terá insumos diferenciados, a partir de sua própria prática, para aplicar em sua docência futura.

Os excertos 4 e 5 apresentam o questionário de Bruno e João, professores pré-serviço que cursam o período noturno, respectivamente, do primeiro e segundo anos do curso de Letras.

Excerto 4. Q2 de Bruno (Professor pré-serviço do $1^{\circ}$ ano de Letras)

Bruno Éramos mediados por uma professora, que no primeiro encontro explicou como funciona[m] as interações. Eu achei fantástico falar com um nativo, já que eu nunca tinha tido esse contato antes e, sem dúvidas, é muito melhor do que a conversação robotizada que eu vivenciei nas escolas. Fazíamos uma interação por semana com duração de 1h. Falávamos 30 minutos em português e 30 minutos em inglês. Era uma interação 100\% aprendizagem, porque minha parceira me corrigia, quando eu falava algo errado ou formulava uma frase errada, e eu também a corrigia. Anotávamos tudo pra estudar depois e tentar utilizar as correções em outra interação. A professora mediadora ajudava as pessoas que tinham dificuldade com a Língua, e sempre pedia pra gente não misturar as duas línguas quando estivéssemos na conversação. Era bem divertido. A YY me ensinou muito e me tranquilizou muito também, porque eu ficava muito encucado com a pronúncia certa e acabava me confundindo. Hoje somos amigos. Nos seguimos no insta e temos o número um do outro e sempre conversamos sobre as notícias de lá e as notícias daqui.

Fonte: Elaboração própria

No caso de Bruno, recém-admitido na universidade, a prática de teletandem é mencionada em seu primeiro semestre. Em sua fala, destacam-se as ações da professora mediadora 
na forma de orientação e auxílio aos participantes e, também, a comparação de interação com um falante nativo e a prática da língua realizada em escolas. Fica claro o apreço de Bruno pela experiência e, também, a afinidade com a parceira. Ao mencionar as estratégias de aprendizagem adotadas (correção e anotação) por eles, o professor préserviço denota a atenção de $Y Y$ ao ensiná-lo e tranquilizá-lo diante de impasses com pronúncia, por exemplo. Quando retrata a continuidade do contato com a parceira por uma mídia social, não encerrado com o término das interações de teletandem, demonstra que a comunicação intercultural pode extrapolar os conteúdos meramente linguísticos e proporcionar vivências interessantes. Concretizam-se, assim, pela aprendizagem, a construção conjunta de conhecimento, o acesso ao outro e a transposição teoria e prática.

Bruno e João compartilham a realização de teletandem logo no primeiro semestre, momento ainda de "ambientação", como se observa no excerto 5.

Excerto 5. Q2 de João (Professor pré-serviço do $2^{\circ}$ ano de Letras)

\begin{tabular}{|l|l|}
\hline João & Fiz Teletandem no primeiro semestre da graduação. Uma aventura, pois estava me \\
ambientando ainda à faculdade. De repente, enquanto olhava os e-mails que tinha \\
recebido, vi a oportunidade (que mais desejava, de forma gratuita) de conversar em \\
Inglês com um estudante dos EUA. Pude durante as conversas que tinha, por intermédio \\
da tecnologia, conhecer o cotidiano e a cultura da minha parceira que era do XX, mas \\
que fazia graduação em XX. Foi uma troca maravilhosa entre nós, a qual permitiu que \\
eu melhorasse a língua estrangeira e, ainda, pudesse ajudá-la no português. No começo, \\
eu era tímido (talvez, por medo de errar), mas era sempre motivado e auxiliado pela \\
companheira. Com isso, aos poucos, fui perdendo a timidez e me desenvolvendo como \\
desejava. \\
Durante o Ensino Médio, como já sabia que seria professor, cobrava-me demais em \\
comparação aos colegas de sala. Queria poder me explanar bem e ser futuramente um \\
ótimo docente. E, durante esse processo, observava todos meus professores - seus \\
erros e feitos bons. Então, felizmente na graduação, posso já dizer que estou rumo ao que \\
queria ser: talkative. E, também, por meio de tudo que (esta universidade) proporciona - \\
através dos professores e suas mediações - vou aprendendo mais. E planejando como \\
será minha prática docente. Os aparatos tecnológicos, sem dúvidas, têm importância \\
durante esse meu percurso e pretendo inseri-los nas minhas aulas.
\end{tabular}

Fonte: Elaboração própria

João reconhece o teletandem como uma oportunidade, muito desejada, de contato com a língua e o falante estrangeiro, de forma gratuita, por meio da tecnologia. Acerca das interações, ele aponta a experiência muito positiva, enquanto "troca" já que menciona oferecimento e recebimento de suporte para a aprendizagem e, dessa forma, o exercício da reciprocidade entre os pares, esperado nas ações em tandem. Observa-se uma autoavaliação que se desencadeia quando João comenta sobre os avanços percebidos em seu desempenho linguístico e na desenvoltura. 
O comentário de João apresenta uma vertente reflexiva e madura acerca do "ser professor". Ele retoma sua vivência no Ensino Médio e a decisão acerca de sua futura profissão: gostaria de se tornar docente. A perda da timidez parece ser algo há tempo desejado para se expressar com desenvoltura e exercer a docência. É interessante observar que João vem, por meio da observação e de preparo, construindo uma trajetória rumo à sua meta, aproveitando as oportunidades, planejando-se, avaliando e autoavaliando-se. Finalmente, reconhece a relevância das tecnologias em seu percurso e afirma que almeja utilizá-las quando de sua futura atuação docente.

A apresentação pessoal realizada por João, a partir da proposta "Apresente-se, por favor, como estudante do curso de Letras que é (você poderá, também, comentar contextos nos quais esteja inserido de ensino, pesquisa, extensão)", corrobora as questões aqui apontadas: a opção pela docência, a paixão pela educação, seu engajamento para atingir seus objetivos futuros, como se pode observar no excerto 6.

Excerto 6. Q1 de João (Professor pré-serviço do $2^{\circ}$ ano de Letras)

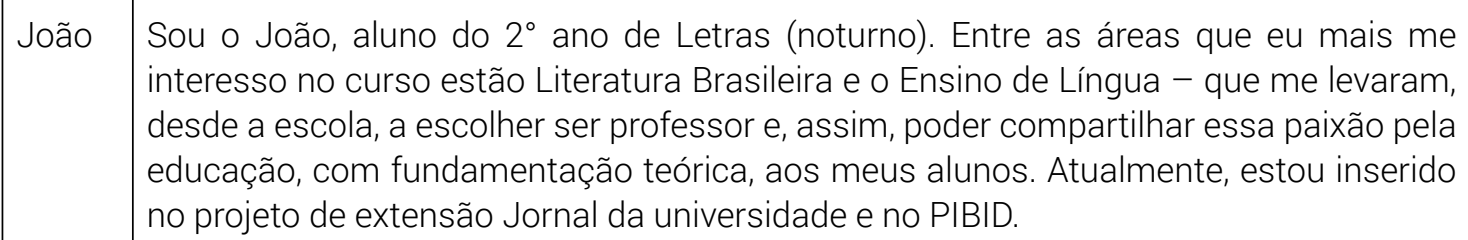

Fonte: Elaboração própria

O relato de João perpassa o processo de formação no curso de Letras e o uso das tecnologias, assim como a resposta apresentada por Bruno à questão "Discorra a respeito de seu processo de formação no curso de Letras e o uso das tecnologias, considerando que você é professor pré-serviço (teacher to be)", no excerto 7.

Excerto 7. Q1 de Bruno (Professor pré-serviço do $1^{\circ}$ ano de Letras)

\begin{tabular}{|l|l|}
\hline Bruno & $\begin{array}{l}\text { Como professor pré-serviço em inglês, eu acredito que o uso da tecnologia em sala de } \\
\text { aula traz um avanço significante para o contato dos alunos com a língua inglesa. No } \\
\text { ensino público, o inglês é visto como dispensável porque os alunos estão exaustos da } \\
\text { maneira maçante como é ensinado. O uso da tecnologia para entreter e educar em } \\
\text { uma outra língua resolveria esse problema. Um Teletandem em escola pública, (mesmo } \\
\text { que utópico) seria algo incrível. As escolas públicas terem parcerias com escolas } \\
\text { americanas para uma teleconferência (mesmo que uma vez por mês) despertaria } \\
\text { um grande entusiasmo nos alunos. O uso do vídeo como forma de ensino também: } \\
\text { curiosidades sobre a cultura, e até mesmo a culinária dos países ingleses, atividades } \\
\text { que possam ensinar e inserir o aluno no cotidiano da língua, porque é assim que eles } \\
\text { enxergam o aprender outro idioma: a prática. Mas para que tudo isso ocorra, é preciso } \\
\text { uma especialização em áreas tecnológicas, que possam ser ajustadas e refinadas pelo } \\
\text { aluno de Letras e futuro professor. É necessário um investimento na educação superior } \\
\text { para que ela gere impacto e mudança na educação pública. }\end{array}$ \\
\hline
\end{tabular}

Fonte: Elaboração própria 
Como se pode notar, Bruno reconhece o potencial das tecnologias e, também, da capacitação para o manejo e utilização nas aulas. É perceptível que sua experiência em teletandem já interfere em sua concepção do ensino/aprendizagem de língua inglesa e, também, de futuro professor, ao vislumbrar práticas mais engajadas e, até mesmo, ações de intercâmbio virtual no contexto da escola pública.

Excerto 8. Q1 de Luciano (Professor pré-serviço do $4^{\circ}$ ano de Letras)

\begin{tabular}{|l|l|}
\hline Luciano & $\begin{array}{l}\text { Com absoluta certeza, os usos da tecnologia ajudaram (e têm ajudado muito) na } \\
\text { minha formação. Desde os textos disponibilizados de maneira digital, acessibilizando } \\
\text { a informação e conteúdo, até a sala de aula em si, onde eram usadas as mídias } \\
\text { digitais conhecidas para auxiliar na compreensão dos conteúdos. É possível } \\
\text { afirmar também que as tecnologias foram importantes nos eventos oferecidos ao } \\
\text { longo da graduação [...] que, muitas vezes, possibilitaram a participação remota de } \\
\text { profissionais e acadêmicos. }\end{array}$ \\
\hline
\end{tabular}

Fonte: Elaboração própria

Apesar de matriculados em anos distintos e distantes, percebe-se que Luciano, da mesma forma que Bruno, reconhece o auxílio das tecnologias no processo de formação docente. Entendemos que tais experiências pessoais irão refletir em concepções de ensino/aprendizagem e práticas futuras.

Acerca da pergunta "Como professor pré-serviço, como você analisa/observa/percebe/ compreende o suporte das tecnologias no ensino?", deparamo-nos com as seguintes respostas:

Excerto 9. Q1 de Aline, Márcio, Luciano e Beatriz (Professores pré-serviço do $1^{\circ}, 2^{\circ}$ e $4^{\circ}$ ano de Letras)

\begin{tabular}{|l|l|}
\hline Aline & $\begin{array}{l}\text { Necessário, pois possibilita diferentes métodos de ensino, principalmente na } \\
\text { modalidade a distância, mas que necessita de aperfeiçoamento tanto no que diz } \\
\text { respeito à instrução dos professores, quanto dos alunos e responsáveis, já que ainda } \\
\text { está longe de ser um meio democrático de ensino e de conhecimento de todos. }\end{array}$ \\
\hline Márcio & $\begin{array}{l}\text { Imagino como um suporte básico, inicialmente, mas que hoje se tornou primordial } \\
\text { pela situação atual em que vivemos, a qual pode ter servido como um catalisador } \\
\text { para o alcance e domínio das tecnologias nas salas de aula. Por isso, imagino que, } \\
\text { quando as aulas retornarem presencialmente, as tecnologias estarão bem mais } \\
\text { presentes do que antes, o que acho muito positivo, pois penso ser uma forma de } \\
\text { diálogo que se aproxima mais do mundo dos alunos modernos. Obviamente, deve } \\
\text { ser sempre repensada, de modo que nunca exclua aqueles que não possuem pleno } \\
\text { acesso. }\end{array}$ \\
\hline
\end{tabular}




\begin{tabular}{|l|l|}
\hline Luciano & $\begin{array}{l}\text { É uma pergunta muito delicada porque a tecnologia tem dois lados: a ferramenta } \\
\text { suportiva do professor e a distração competitiva para o aluno. Então administrar } \\
\text { a tecnologia a favor, não só do professor, mas do aluno também, é uma tarefa } \\
\text { complexa, mas que com toda certeza gera mais frutos do que ervas daninhas. }\end{array}$ \\
\hline Beatriz & $\begin{array}{l}\text { Todos temos que nos familiarizar ao uso das mídias digitais para o dia a dia, e } \\
\text { acredito que na rede pública esse primeiro contato é intermediado pela escola. Como } \\
\text { professora pré-serviço quero trazer esse conhecimento para as salas de aulas de } \\
\text { acordo com a disponibilidade dos alunos e dos recursos da escola. }\end{array}$ \\
\hline
\end{tabular}

Fonte: Elaboração própria

Os dados do excerto 9 revelam que os professores pré-serviço em questão compreendem o uso das tecnologias como importantes já que propiciam inovação e aproximação, ressaltando-se, também, o momento atual. Todavia, reconhecem a relevância de capacitação docente e, também, discente. É importante salientar, como afirma e exemplifica Luciano, a complexidade que engloba a temática considerando-se seus aspectos positivos (de suporte) e, também, negativos (distração). Salientamos, ainda, a questão de acesso e democratização que variam segundo disponibilidade, conhecimento, habilidades e recursos.

Ressaltando-se o momento pandêmico atual, o suporte das tecnologias e a imposição do ensino/aprendizagem remotos, compartilhamos o posicionamento de Aline ao afırmar que "está longe de ser um meio democrático de ensino e de conhecimento de todos". A exclusão, ainda tão gritante em setores variados em nosso país, acentua a complexidade mencionada por Luciano. Todavia, entendemos que o uso significativo, a capacitação para o manejo e as experiências pessoais devam ser maximizadas, principalmente em contexto de formação docente para que possam ecoar em suas práticas futuras.

Passamos, a seguir, para as considerações finais do trabalho aqui apresentado com vistas à reflexões acerca do impacto e oportunidades mediadas pelas TDICs a estudantes do curso de Letras em seu processo de formação.

\section{Considerações finais}

A utilização das tecnologias no processo educacional tornou-se inquestionável e, algumas vezes, inquietante por razões já expostas neste trabalho. Compreendemos que o uso consciente de forma a fomentar o engajamento de educadores e educandos possa minimizar assimetrias. E, para tal, não podemos deixar de considerar a formação docente.

Entende-se que as atividades telecolaborativas têm promovido o desenvolvimento crítico-reflexivo e a construção conjunta de conhecimento. Dessa forma, a sala de aula é expandida com vivências reais e significativas e oportunizam-se experiências autênticas 
de comunicação em língua estrangeira com parcerias internacionais. Assim sendo, até alunos menos desenvoltos passam a protagonizar a estruturação do conhecimento e assumir espaços e ações nem sempre explorados no ambiente formal de aprendizagem.

Voltando nosso olhar para estudantes no curso de Letras e para ações telecolaborativas realizadas na universidade, observamos que as tecnologias podem potencializar o contato com os povos, suas línguas e culturas e desencadear questões e aprendizagens que extrapolam a língua. Podemos mencionar, por exemplo, o exercício da autonomia, da reflexão, da autoavaliação no gerenciamento da parceria intercultural. Dessa forma, experiências linguísticas, tecnológicas e pessoais podem modificar concepções e incrementar a atuação futura dos professores pré-serviço.

Perpassa a voz dos professores pré-serviço que as tecnologias podem apresentar contribuições e incrementar o ensino/aprendizagem, mas, também, acentuar a exclusão. De qualquer maneira, reconhecemos que articular situações inovadoras e caminhos diversificados ao conhecimento possa catalisar o processo de formação docente e inspirar perspectivas e práticas futuras. A realização do teletandem, aqui descrita, evidencia apenas um modo para complementar o trabalho presencialmente desenvolvido em um curso de graduação em Letras, como aqui enfocado.

\section{REFERÊNCIAS}

ALARCÃO, I. Professores reflexivos em uma escola reflexiva. 8. ed. São Paulo: Cortez, 2011.

ALMEIDA, M. E. B. Apresentação. In: BACICH, L.; MORAN. J. M. Metodologias ativas para uma educação inovadora: uma abordagem teórico-prática. Porto Alegre: Penso, 2018. p. ix-xiii.

ARAGÃO, R.; CAJAZEIRA, R. Reflexões sobre a formação de professores: relatos sobre o uso de tecnologias educacionais na experiência docente. In: JESUS, D. M.; MACIEL, R. F. (org.). Olhares sobre tecnologias digitais: linguagens, ensino, formação e prática docente. Campinas: Pontes Editores, 2015. p. 301-324.

BRAMMERTS, $\mathrm{H}$. Autonomous language learning in tandem. In: LEWIS, T.; WALKER, L. (ed.). Autonomous Language Learning In-Tandem. Sheffield, UK: Academy Electronic Publications, 2003. p. 27-36.

BURNS, A. Collaborative action research for English language teachers. Cambridge: CUP, 1999. 
DELLILE, K. H.; CHICHORRO FERREIRA, A. (ed.). Aprendizagem autónoma de línguas en Tandem. Lisboa: Colibri, Faculdade de Letras da Universidade de Coimbra, 2002.

GARCIA, D. N. M.; FIORUCI, N. E. A.; FREITAS, P. C. B. As ações em teletandem no processo de ensino/aprendizagem de línguas estrangeiras e na formação de professores. In: SOUZA, F. M.; CARVALHO, K. C. H. P.; MESSIAS, R. A. L. Telecolaboração, ensino de línguas e formação de professores: demandas do século XXI. São Paulo: Mentes Abertas; Campina Grande: EdUEPB, 2020. p. 105-127.

LITTLE, D.; USHIODA, E.; APPEL, M.-C.; MORAN, J.; O'ROURKE, B.; SCHWIENHORST, K. Evaluating tandem language learning by e-mail: Report on a bilateral project. (Report $\mathrm{N}^{\circ}$ FL 025 831). Dublin, Ireland: CLCS occasional paper N 55. (ERIC Document Reproduction Service NED430397), 1999.

LÜDKE, M.; ANDRÉ, M. E. D. A. Pesquisa em educação: abordagens qualitativas. São Paulo: EPU, 1986.

MORAN, J. M. Ensino e Aprendizagem inovadores com apoio de tecnologias. In: MORAN, J. M.; MASETTO, M. T.; BEHRENS, M. A. Novas tecnologias e mediação pedagógica. Campinas: Papirus, 2013. p. 11-72.

MORAN, J. M.; MASETTO, M. T.; BEHRENS, M. A. Novas tecnologias e mediação pedagógica. Campinas: Papirus, 2013.

O'DOWD, R. From telecollaboration to virtual exchange: state-of-the-art and the role of UNICollaboration in moving forward. Journal of Virtual Exchange, v. 1, p. 1-23, 2018.

PRENSKY, M. Digital Natives, Digital Immigrants. On the Horizon, Bradford, v. 9, n. 5, p. 2-6, 2001.

REZENDE JR., E.; MESSIAS, R. A. L. Formação de professores de língua estrangeira (LE) em um contexto telecolaborativo. In: SOUZA, F. M.; CARVALHO, K. C. H. P.; MESSIAS, R. A. L. Telecolaboração, ensino de línguas e formação de professores: demandas do século XXI. São Paulo: Mentes Abertas; Campina Grande: EdUEPB, 2020. p. 43-58.

RICOEUR, P. Hermeneutics and the Human Sciences: Essays on Language, Action and Interpretation. Cambridge: Cambridge University Press, 1981.

RYDER, L.; LYNCH, L. Y. Understanding Tensions: Activity Systems Analysis of Transpacific Collaboration. CALICO Journal, v. 31, n. 2, p. 201-220, 2014. 
SALOMÃO, A. C. B. A cultura e o ensino de língua estrangeira: perspectivas para a formação continuada no projeto teletandem. 2012. Tese (Doutorado em Estudos Linguísticos) - Instituto de Biociências, Letras e Ciências Exatas, Universidade Estadual Paulista "Júlio de Mesquita Filho", São José do Rio Preto, 2012.

SCHWIENHORST, K. Matching pedagogy and technology - Tandem learning and learner autonomy in online virtual language environments. Language Teaching On-Line, 1998, s/p.

TELLES, J. A. Teletandem and performativity. Revista Brasileira de Linguística Aplicada, v. 15, n. 1, p. 1-30, 2015.

VAN MANEN, M. Researching Lived Experience: human science for an action sensitive pedagogy. London, Ontario: Althouse Press, 1990.

VETROMILLE-CASTRO, R.; FERREIRA, K. S. Formação, redes sociais na formação de professores de línguas. In: ARAÚJO, J.; LEFFA, V. Redes Sociais e ensino de línguas: o que temos de aprender. São Paulo: Parábola Editorial, 2016. p. 155-170. 